Article

\title{
Optimal Monazite Concentration Processes for the Extraction of Uranium and Thorium Fuel Material
}

\author{
Olga Fedorova ${ }^{1}$, Elizaveta Vershinina ${ }^{2}$, Svetlana Krasitskaya ${ }^{2}$, Ivan Tananaev ${ }^{1,2,3, *}$, \\ Boris Myasoedov ${ }^{3}$ and Marco Vocciante ${ }^{4, *}$ iD \\ 1 Ozyorsk Technological Institute, National Research Nuclear University (MEPhI), 456780 Ozyorsk, Russia; \\ ovfedorova@mephi.ru \\ 2 School of Natural Sciences, Far Eastern Federal University, 690090 Vladivostok, Russia; \\ geokhi@mail.ru (E.V.); krasitskaya.sg@dvfu.ru (S.K.) \\ 3 Frumkin Institute of Physical Chemistry and Electrochemistry, Russian Academy of Sciences, \\ 119991 Moscow, Russia; bfmyas@mail.ru \\ 4 Department of Chemistry and Industrial Chemistry, University of Genova, 16146 Genova, Italy \\ * Correspondence: tananaev.ig@dvfu.ru (I.T.); marco.vocciante@unige.it (M.V.)
}

Received: 3 August 2020; Accepted: 30 August 2020; Published: 4 September 2020

check for updates

\begin{abstract}
The optimal conditions for the nitric acid dissolution of precipitates of hydroxides and hydrated oxides of rare-earth elements, uranium, and thorium obtained after autoclave alkaline opening of samples of monazite concentrate have been determined. The distribution of radioactive impurities between the solid phase and the solution in the processes of alkaline opening, dephosphorization, and acid dissolution of the pulp was studied. Two options are proposed for the extraction of uranium and thorium in the presence of rare earth elements, followed by separation of the components using tributyl phosphate of various contents in the carbon diluent.
\end{abstract}

Keywords: monazite; autoclave leaching; flow chart; rare earth elements; thorium; uranium; radium; separation; extraction

\section{Introduction}

The development of nuclear energy programs is presently underway in several countries. In particular, it is included in the list of priority areas of economic modernization for the Russian Federation. The nuclear power industry in the Russian Federation, as in many other countries, was based on the use of the uranium-plutonium fuel cycle, mainly developed to address military problems [1]. However, in the medium-term-probably already within a few decades-the application of the thorium-uranium fuel cycle, based on the use of thorium, for the development of nuclear energy [2] will acquire increasing importance, due to the relative abundance of thorium in nature. Indeed, unlike uranium raw materials, the thorium world reserves (especially in the Russian Federation) are practically unbounded. The Th content of the earth's crust is $8 \times 10^{-4} \mathrm{wt} \%$ [3], which is about 3.5 times higher than that of U. About 120 thorium-containing minerals are known [3-7].

Furthermore, the use of thorium provides a number of additional advantages.

Indeed, the extraction of thorium is an essential task in the industry of rare-earth elements (REEs) which are associated with several thorium raw materials [8]. Another considerable advantage when using the thorium-uranium cycle is the elimination of the production of plutonium and trans-plutonium elements, which not only reduces the risk of proliferation of fissile materials, but also reduces the amount of radioactive waste compared with the uranium-plutonium cycle [4]. The introduction and use of the thorium-uranium cycle in nuclear energy can ensure the environmentally safe development of the industry through the use of approaches that exclude the accumulation of long-lived radioactive waste [9]. 
Additionally, equipment investment and operation costs are considerably lower when using thorium fuel elements because the reactor volume is reduced by a factor of 2-3 for the same amount of energy production and the reactor can be operated continuously for an estimated 50 years without fuel reloading [10].

In view of the undoubted advantages of using the thorium-uranium cycle, it is both important and relevant to search for new, promising sources of thorium raw materials and to create innovative technologies for their processing. The most significant minerals for the industrial extraction of Th are monazite, loparite, and pyrochlore.

The distribution of these minerals in the Russian Federation is briefly reviewed in the next lines. Euxenite sources are located in the territory of the Kola Peninsula [9-12] with a total thorium content of up to 160 thousand tons [13,14], whereas the Tomtorskoye deposits (monazite-pyrochlore) [15] and those of Novotroitskoye, Tarak, Bashelavskoye, Sanarskoye, and Baleyskoye (monazite)—containing up to $5.1-8 \%$ of $\mathrm{ThO}_{2}$ [16] — provide promising opportunities of exploitation. Deposits of tantalite are presently exploited at Etykinsky, Vishnyakovsky, whereas minerals of pyrochlore are extracted at the sites of Tatarsky and Katuginsky [17]. Abandoned sites include Orlovsky (tantalite) and Beloziminsky (pyrochlore) [18]. In total, over 1500 thorium-containing deposits and ore occurrences with reserves of Th up to 1.7 million tons are available in the Russian Federation [10-13].

One of the most important sources of Th production is monazite mineral concentrate presently being stored at the UralMonatsit State Institution near Krasnoufimsk, Sverdlovsk Region. Its chemical formula is $\mathrm{Ce}, \mathrm{La}, \mathrm{Th}, \mathrm{Ca}\left[\mathrm{PO}_{4}, \mathrm{SiO}_{4}, \mathrm{SO}_{4}\right]$; it contains from $50 \%$ to $68 \%$ of $\mathrm{REE}$ oxides; from $22 \%$ to $31.5 \%$ of $\mathrm{P}_{2} \mathrm{O}_{5}$; from $10 \%$ to $28 \%$ of $\mathrm{ThO}_{2}$, including isomorphic $\mathrm{ZrO}_{2}$ (up to $7 \%$ ) and $\mathrm{SiO}_{2}$ (up to $6 \%$ ) and impurities of $\mathrm{MgO}, \mathrm{MnO}, \mathrm{PbO}, \mathrm{Fe}_{2} \mathrm{O}_{3}, \mathrm{Al}_{2} \mathrm{O}_{3}$ [19].

The classical technologies for processing monazite, based mainly on the sulfuric or alkaline opening of mineral raw materials followed by extraction of valuable components, are described in [20]. An alternative approach is based on the use of supercritical fluid extraction with carbon dioxide containing tributyl phosphate adducts [21], D2EGFK [22] and other reagents [23-27].

In the present work, new approaches for optimizing the technologies for alkaline processing of monazite [28] are proposed, including grinding of the raw material, acid dissolution of precipitates of REEs, uranium, and thorium oxides-hydroxides, followed by their extraction and separation.

\section{Materials and Methods}

The experiments that form the basis of this study were conducted employing the monazite concentrate with a bulk density of $2.8 \mathrm{~g} / \mathrm{cm}^{3}$ stored at a branch of the UralMonatsit Regional State Institution (the average composition is given in Table 1).

Monazite grinding was carried out using the SM-3 cone crusher (Vilitek LLC, RF, Moscow, Russia). Monazite, disintegrated in the crusher, was dispersed on sieves with multiple returns of a large fraction to the head operation. In the study, a significant amount of monazite concentrates with different grain sizes of $<0.05 \mathrm{~mm}, 0.05-0.125 \mathrm{~mm}, 0.125-0.25 \mathrm{~mm}$ and $0.25-0.5 \mathrm{~mm}$ was investigated.

Alkaline opening of the monazite concentrate was carried out in a stainless-steel metal apparatus, and the regimes for transferring the formed pulp to the nitric acid medium were worked out in quartz vessels.

For the opening of raw mineral materials, $\mathrm{NaOH}$ of the "chemically pure" qualification was used. Monazite concentrate powder of a certain fraction and known mass was placed in an autoclave, and $\mathrm{NaOH}$ solution of a given concentration and volume was introduced.

Literature data confirm [29] that the most important factors affecting the completeness of alkaline opening of monazite concentrate are contact time, temperature, and degree of fineness of the initial material; on the contrary, a change in the alkali content in the solution and the solid-to-liquid ratio affect it to a lesser extent. The optimal conditions for the mentioned process were found to be: a degree of fineness of particles from 0.05 to $0.125 \mathrm{~mm}$ at $[\mathrm{NaOH}]=19 \mathrm{~mol} / \mathrm{L}$, a solid-to-liquid ratio $=1: 4$ and a contact time of $3 \mathrm{~h}$ at $160^{\circ} \mathrm{C}$. 
Table 1. The average composition of monazite concentrate located at the UralMonatsit State Institution near the town of Krasnoufimsk, Sverdlovsk Region. * = calculated value.

\begin{tabular}{cc}
\hline Composition & Content, wt\% \\
\hline $\mathrm{Ln}_{2} \mathrm{O}_{3}$ & 67.478 \\
$\mathrm{P}_{2} \mathrm{O}_{5}{ }^{*}$ & 23.692 \\
$\mathrm{ThO}_{2}$ & 6.921 \\
$\mathrm{Fe}_{2} \mathrm{O}_{3}$ & 0.522 \\
$\mathrm{Al}_{2} \mathrm{O}_{3}$ & 0.077 \\
$\mathrm{SiO}_{2}$ & 0.195 \\
$\mathrm{TiO}_{2}$ & 0.144 \\
$\mathrm{CaO}$ & 0.631 \\
$\mathrm{MgO}$ & 0.135 \\
$\mathrm{U}_{3} \mathrm{O}_{8}$ & 0.179 \\
$\mathrm{WO}_{3}$ & 0.001 \\
$\mathrm{ZrO}$ & 0.014 \\
$\mathrm{ZnO}$ & 0.003 \\
$\mathrm{CdO}^{\mathrm{CbO}}$ & 0.003 \\
\hline
\end{tabular}

At the end of the experiment, the autoclave was cooled to $100{ }^{\circ} \mathrm{C}$, the obtained alkaline pulp was diluted with hot distilled water (1:1) and filtered. The precipitate was additionally washed from phosphate ions with water, dried, and further opened by the action of $\mathrm{HNO}_{3}$.

The chemical composition of the raw source material and precipitate after autoclave alkaline treatment was characterized using the X-ray phase ID analysis method using the DRON-4-13 diffractometer (Burevestnik Innovation Center of the Alrosa Group, RF, St. Petersburg, Russia). To identify the compound, the result was compared with diffractograms of the ICPDS catalog.

In the experiments on the acid dissolution of REE oxides/hydrated oxides, uranium elements and impurity elements ( $\mathrm{Zr}$, Si, etc.), samples weighing $1 \mathrm{~g}$ were placed in $100-\mathrm{mL}$ quartz glasses, 5 to $50 \mathrm{~mL}$ of chemically pure $7-9 \mathrm{~mol} / \mathrm{L} \mathrm{HNO}_{3}$ was introduced after heating to $80-95^{\circ} \mathrm{C}$ for $1-5 \mathrm{~h}$. In some experiments, $0.1 \mathrm{~mL}$ of $30 \% \mathrm{H}_{2} \mathrm{O}_{2}$ was added to the solution. The insoluble part of the precipitate was dried, weighed, and the degree of opening of the sample $(\mathrm{S}$, in $\mathrm{wt} \%)$ was determined by the difference with the mass of the sample taken from the concentrate.

The activity of the resulting precipitates and solutions was measured using an SEG-1PPD semiconductor gamma spectrometer and a Quantulus 1220 alpha-radiation spectrometer. The total activity of the solutions was determined using a Progress-alpha alpha-radiometer. The relative error of gamma spectrometric was $\pm 10 \%$, alpha spectrometric, $\pm 20 \%$. The application of this technique made it possible to unambiguously identify and determine the content of ${ }^{232} \mathrm{Th},{ }^{228} \mathrm{Th}$ and ${ }^{224} \mathrm{Ra}$ in the analyzed samples.

To isolate pure Th and U compounds from technological solutions, the authors applied the extraction method using tributyl phosphate solutions with different volume fractions of the extractant in the S-13 carbon diluent. The extraction part of the work was carried out in glass separation funnels. As extractants, solutions of chemically pure tributyl phosphate were used. Two model solutions were used in the experiment, containing $300 \mathrm{mg} / \mathrm{L}$ of U, $2500 \mathrm{~g} / \mathrm{L}$ of Th, $10,000 \mathrm{mg} / \mathrm{L}$ of Ce, $5400 \mathrm{mg} / \mathrm{L}$ of La and $4500 \mathrm{mg} / \mathrm{L}$ of $\mathrm{Nd}$ (the total REE content was $19,900 \mathrm{mg} / \mathrm{L}$ ) differing in the $\mathrm{HNO}_{3}$ content as 3 and $1 \mathrm{~mol} / \mathrm{L}$, respectively. The experiments were carried out at room temperature, the ratio of the organic and aqueous phases upon contact was 0.1.

\section{Results and Discussion}

\subsection{Studying the Distribution of Radioactive Impurities during Autoclave Leaching and Subsequent Processing}

It is known that in the averaged composition of the Krasnoufimsk monazite sample, there is not only up to $67 \%$ of the sum of high-priced rare-earth oxides, but also $6.9 \%$ of thorium oxide $\mathrm{ThO}_{2}$ and $0.18 \%$ of uranium oxides (Table 1 ). Thus, the initial mineral raw material is a radioactive material containing alpha emitters $\left({ }^{232} \mathrm{Th},{ }^{235} \mathrm{U},{ }^{238} \mathrm{U}\right)$ and their decay products $\left({ }^{228} \mathrm{Th},{ }^{224} \mathrm{Ra},{ }^{226} \mathrm{Ra},{ }^{212} \mathrm{Bi},{ }^{220} \mathrm{Rn}\right.$, 
${ }^{222} \mathrm{Rn}$, and $\left.{ }^{212,214,216,218} \mathrm{Po}\right)$, some of which are gamma-active $\left({ }^{228} \mathrm{Ac},{ }^{212,214} \mathrm{Bi},{ }^{208} \mathrm{Tl},{ }^{212} \mathrm{~Pb}\right)$. The chain of radioactive transformations of ${ }^{232} \mathrm{Th}$ is shown in Figure 1 diagram below:

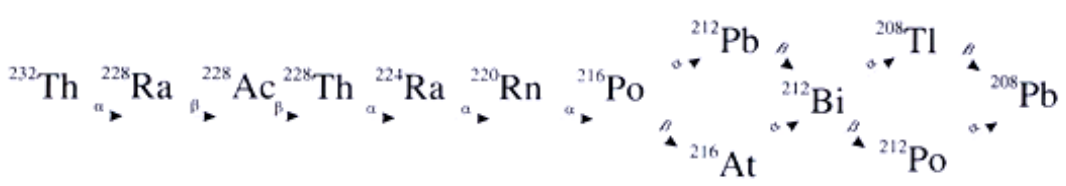

Figure 1. Chain of radioactive transformations of ${ }^{232} \mathrm{Th}$.

Therefore, before performing the technical operations of opening and extracting of REEs, uranium, and thorium from monazite concentrate, it is necessary to collect the necessary information on the distribution of radioactive impurities during processing and on the activity levels of liquid and solid phases.

In the course of the research, the following substances were subjected to radionuclide analysis: (1) precipitation of the obtained REE oxides/hydroxide compounds, elements of the uranium series and impurity elements; (2) a phosphate-alkaline solution; (3) a solution obtained by dissolving hydroxides in nitric acid; and also (4) the part of the solid phase that did not dissolve, which are formed in the technological process (Figure 2) [20].

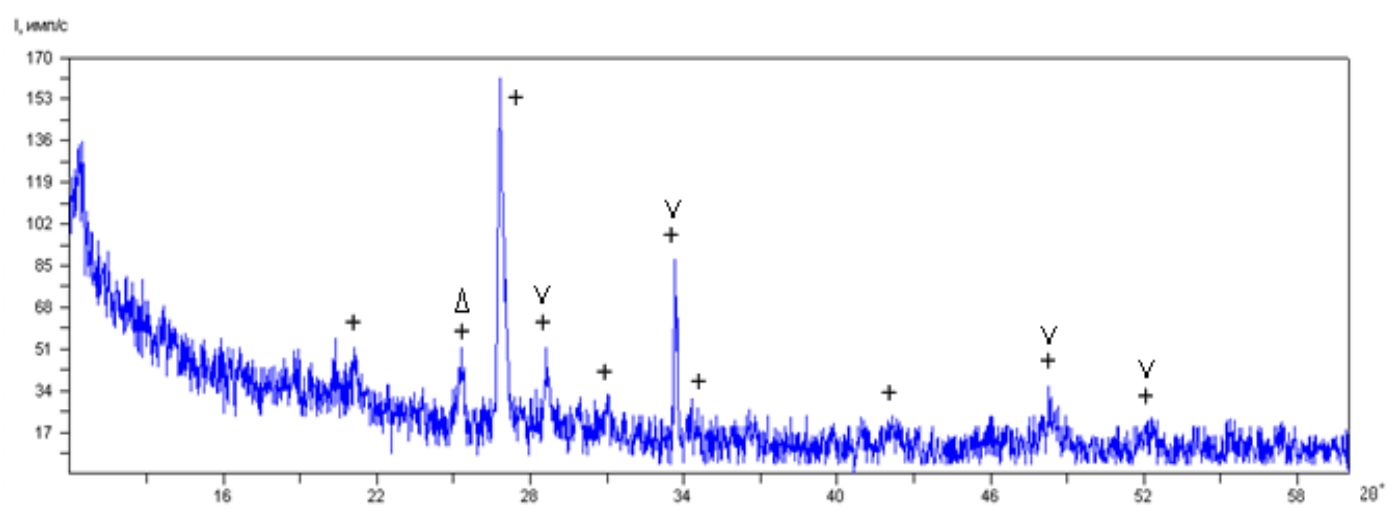

(a)

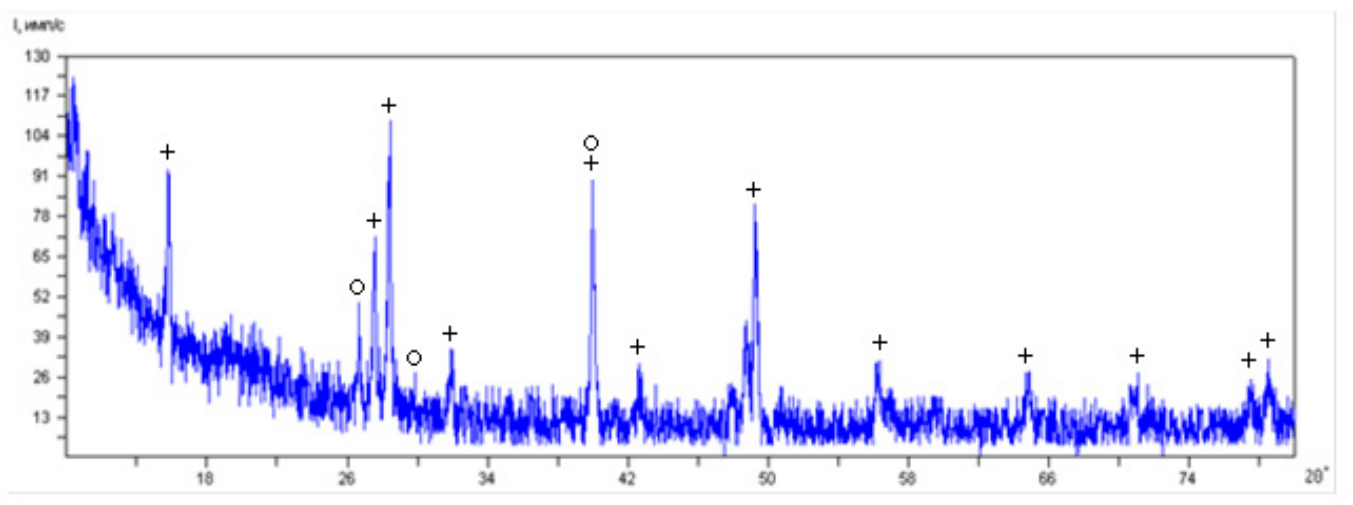

(b)

Figure 2. Diffractograms of (a) the initial sample of monazite concentrate; phase composition: " + " $(\mathrm{Ce}, \mathrm{La}, \mathrm{Nd}) \mathrm{PO}_{4}, \operatorname{Pr}\left(\mathrm{PO}_{3}\right)_{3} ; " \mathrm{v}$ " $\mathrm{UO}_{2} ; " \Delta^{\prime} \mathrm{TiO}_{2} ;(\mathbf{b})$ the product of alkaline autoclave opening of monazite concentrate under optimal process conditions; phase composition: " + " $\operatorname{Pr}(\mathrm{OH})_{3}, \mathrm{Ce}(\mathrm{OH})_{3}$, $\mathrm{Nd}(\mathrm{OH})_{3} ; "$ o" $\mathrm{Ce}_{2} \mathrm{O}_{3}$. 
It was found that, basically, all gamma and alpha-active radionuclides are concentrated in the deposits of REE oxides/hydroxides, elements of the uranium series, and impurity elements obtained as a result of alkaline treatment of monazite concentrate (Tables 2 and 3).

Table 2. Activity $(\mathrm{kBq} / \mathrm{L})$ determined by gamma spectrometry of samples: (a) oxide and hydrated precipitates of REEs, uranium and thorium obtained after autoclave processing of monazite concentrate; (b) phosphate-alkaline solutions and wash water; (c) nitric acid solution obtained by dissolving oxide and hydrated sediments of REEs, uranium and thorium.

\begin{tabular}{ccccc}
\hline \multirow{2}{*}{$\begin{array}{c}\text { Maternal } \\
\text { Radionuclide }\end{array}$} & $\begin{array}{c}\text { Radionuclide Used for } \\
\text { Calculations }\end{array}$ & $\mathbf{a}$ & $\mathbf{b}$ & $\mathbf{A c t i v i t y , ~} \mathbf{k B q} / \mathbf{k g}$ \\
\cline { 2 - 4 } Th-232 & Ac-228 & 281 & $>0.1$ & 5.2 \\
& $\mathrm{Bi}-212$ & 285 & Not found & Not found \\
& $\mathrm{Pb}-212$ & 265 & $>0.1$ & 7.3 \\
$\mathrm{Tl}-208$ & 229 & $>0.1$ & 5.1 \\
\hline U-238 & Th-234 & 131 & & Below detection \\
& Pa-234 & 139 & Below detection & limit \\
& $\mathrm{Bi}-214$ & 29 & limit & \\
\hline
\end{tabular}

Table 3. Activity $(\mathrm{kBq} / \mathrm{kg})$ determined by alpha spectrometry of the samples: (a) precipitation of oxide and hydrated rare-earth elements (REEs), uranium and thorium compounds obtained after autoclave processing of monazite concentrate; (b) phosphate-alkaline solutions and wash water; (c) nitric acid solution obtained by dissolving oxide and hydrated sediments of REEs, uranium and thorium.

\begin{tabular}{cccccccc}
\hline Radionuclide & Th-232 & Th-228 & Ra-224 & Rn-220 & Po-212 & Po-216 & $\sum$ \\
\hline a & 676 & 451 & 197 & 288 & 102 & 98 & 3470 \\
b & $<0.1$ & $<0.1$ & $<0.1$ & $<0.1$ & $<0.1$ & $<0.1$ & - \\
c & 4.5 & 5.3 & 2.3 & 3.5 & 1.6 & 1.7 & 31.6 \\
\hline
\end{tabular}

The analysis of alpha and gamma spectra showed that the main identifiable radionuclides in the samples were ${ }^{228} \mathrm{Ac},{ }^{212,214} \mathrm{Bi},{ }^{212,214} \mathrm{~Pb},{ }^{208} \mathrm{Tl},{ }^{228,232,234} \mathrm{Th},{ }^{212} \mathrm{Po},{ }^{224} \mathrm{Ra}$, and ${ }^{234} \mathrm{~Pa}$.

On the contrary, in all experiments, the phosphate-alkaline solution obtained after the autoclave opening of the concentrate did not contain any radioactive impurities, as evidenced by the results of both gamma and alpha spectrometric measurements. In this regard, it can be concluded that the phosphate-alkaline (clarified) solutions formed in the processing, as well as the wash water, are free from radionuclides of uranium, thorium, and radium; they do not require special treatment and can be used to obtain a by-product, phosphate fertilizers.

It was shown that the solution obtained by dissolving hydroxides and hydrated oxides of REEs, uranium, thorium hydroxides in nitric acid contained impurities of radium-224 (Tables 2 and 3). However, due to its short half-life (about 4 days), the purification of the nitric acid phase from radium-224 is not expedient. In the authors' opinion, the sludge that was not dissolved in $\mathrm{HNO}_{3}$ in terms of the content of radionuclides can be classified as industrial waste that does not require separate burial.

\subsection{Opening of Monazite Concentrate}

The heterogeneous high-temperature process of the hydroxide opening of monazite concentrate is carried out according to the general scheme:

$$
\begin{aligned}
& (\mathrm{REE}) \mathrm{PO}_{4}+3 \mathrm{NaOH}=(\mathrm{REE})(\mathrm{OH})_{3}+\mathrm{Na}_{3} \mathrm{PO}_{4} \\
& \mathrm{Th}_{3}\left(\mathrm{PO}_{4}\right)_{4}+12 \mathrm{NaOH}=3 \mathrm{Th}(\mathrm{OH})_{4}+4 \mathrm{Na}_{3} \mathrm{PO}_{4}
\end{aligned}
$$

In this regard, according to the above scheme and taking into account the optimal conditions recommended in the literature [28] for the complete conversion of monazite concentrate into the form 
of hydroxides and hydrated metal oxides in an autoclaved alkaline environment, it was necessary to determine: (1) the optimal conditions for the quantitative washing of the resulting hydroxide precipitates from $\mathrm{Na}_{3} \mathrm{PO}_{4}$ and $\mathrm{NaOH}$ after autoclave processing; (2) the optimal conditions for the dissolution of hydroxide pulp in nitric acid; (3) approaches to the selective isolation and separation of target components: REEs, uranium, and thorium from the substance purified from natural radionuclides by the extraction method.

In the first stage, the conditions for washing hydroxide precipitates obtained after the autoclave opening of monazite concentrate from the remainders of $\mathrm{NaOH}$ and phosphate ions, primarily $\mathrm{Na}_{3} \mathrm{PO}_{4}$, were studied. During the tests, it was experimentally observed that the quantitative washing of $10 \mathrm{~g}$ of the product of opening the monazite concentrate from both $\mathrm{NaOH}$ and $\mathrm{Na}_{3} \mathrm{PO}_{4}$ to the content of phosphate ions in the wash water $<10^{-3} \mathrm{~g} / \mathrm{L}$ is achieved by a single wash with $100 \mathrm{~mL}$ of distilled water at $80^{\circ} \mathrm{C}$ and contact time of $10 \mathrm{~min}$. Trisodium phosphate in the environment of the alkali remaining after processing (up to $30 \%$ ) at $100-110{ }^{\circ} \mathrm{C}$ easily crystallizes and is separated by a "blue ribbon" filter. In this case, $\mathrm{Na}_{3} \mathrm{PO}_{4}$ is isolated separately as a valuable by-product as a mineral fertilizer, and residual sodium hydroxide can be reused in experiments.

The second stage of research was focused on determining the optimal conditions for the dissolution of the obtained precipitation of hydroxides and hydrated oxides of REEs, uranium, and thorium in nitric acid after the autoclave processing of the concentrate.

To this purpose, the samples of monazite concentrate were autoclaved with alkali according to the procedures described in the previous section.

In the X-ray diffraction patterns of alkaline autoclave products there are no peaks assigned to the initial phases in the monazite concentrate, which indirectly confirms the completion of its opening (Figure 2).

The washed and dried samples of hydroxides and hydrated oxides of REEs, uranium, and thorium were dissolved in $\mathrm{HNO}_{3}$ depending on acid concentration, temperature, Solid/Liquid phase ratios $(\mathrm{S} / \mathrm{L})$, and their contact times. The resulting solubility is shown in Table 4.

It appears that the main factors affecting the completeness of the dissolution of hydroxides and hydroxide precipitates of the concentrate components were the contact time and the concentration of $\mathrm{HNO}_{3}$. The $\mathrm{S} / \mathrm{L}$ ratio and temperature values also affect the completeness of the dissolution of precipitation, but to a lesser extent. Under optimal conditions, the degree of opening of monazite concentrate reached values of up to $90-95 \%$. On the contrary, a decrease in the contact time, $\mathrm{S} / \mathrm{L}$, and temperature, as well as an increase in the degree of fineness of the substance, reduces the degree of alkaline opening by $20-40 \%$.

The introduction of an activating reagent $\mathrm{H}_{2} \mathrm{O}_{2}$ in the range from 0.01 to $0.1 \mathrm{~mol} / \mathrm{L}$ does not significantly affect the degree of opening of the concentrate.

Based on the conducted research, optimal conditions for opening precipitates of rare-earth hydroxides, uranium, and thorium in $\mathrm{HNO}_{3}$ are proposed: for $1 \mathrm{~g}$ of substance, $50 \mathrm{~mL}$ of $9 \mathrm{~mol} / \mathrm{L}$ $\mathrm{HNO}_{3}$, and heating for $3 \mathrm{~h}$ at $90{ }^{\circ} \mathrm{C}$ without adding hydrogen peroxide.

In the third stage, two approaches were proposed for the extraction of uranium, thorium, and REEs from nitric acid solutions during the processing of monazite concentrate.

Quantitative extraction separation of REEs, uranium, and thorium with the simultaneous purification of impurity chemical elements is a non-trivial problem. The main known technologies for opening monazite raw materials were focused on the complete separation of the target rare-metal products, while the separation of fractions of elements of the uranium series and thorium was a necessary stage guaranteeing radioactive purification from REEs [30].

In the present study, two approaches were considered that were directly oriented to the extraction of thorium with a high yield of extraction from the mixture as a promising component of the thorium-uranium fuel cycle. The first approach was an attempt to move the components into two selective streams: a uranium stream and a stream of REEs and thorium. In the second approach, the separation of the components was carried out by co-separation of uranium and thorium into 
one selective stream followed by separation, and REEs into the second selective stream, followed by purification of rare-metal products by known methods at the second stage of the process.

Table 4. The dependence of the solubility of precipitation of hydroxides of REEs, Th, U on the dissolution conditions. Sample weight $1 \mathrm{~g}$.

\begin{tabular}{|c|c|c|c|c|c|}
\hline No & $\mathrm{T}\left({ }^{\circ} \mathrm{C}\right)$ & $t(\mathrm{~h})$ & {$\left[\mathrm{HNO}_{3}\right](\mathrm{M})$} & Solid/Liquid (g/mL) & S (\%) \\
\hline 1 & \multirow{11}{*}{80} & \multirow{6}{*}{1.0} & 7.0 & $1: 25$ & 65.9 \\
\hline 2 & & & 8.0 & $1: 25$ & 66.2 \\
\hline 3 & & & 9.0 & $1: 10$ & 66.9 \\
\hline 4 & & & 9.0 & $1: 25$ & 69.0 \\
\hline 5 & & & 9.0 & $1: 50$ & 69.1 \\
\hline 6 & & & 7.0 & $1: 25$ & 69.5 \\
\hline 7 & & \multirow[t]{3}{*}{2.0} & 8.0 & $1: 25$ & 69.8 \\
\hline 8 & & & 9.0 & $1: 25$ & 72.1 \\
\hline 9 & & & 7.0 & $1: 25$ & 71.5 \\
\hline 10 & & \multirow[t]{2}{*}{3.0} & 8.0 & $1: 25$ & 74.5 \\
\hline 11 & & & 9.0 & $1: 25$ & 76.4 \\
\hline 12 & \multirow{11}{*}{90} & \multirow{3}{*}{1.0} & 7.0 & $1: 25$ & 76.2 \\
\hline 13 & & & 8.0 & $1: 25$ & 79.2 \\
\hline 14 & & & 9.0 & $1: 25$ & 82.0 \\
\hline 15 & & \multirow{3}{*}{2.0} & 7.0 & $1: 25$ & 79.2 \\
\hline 16 & & & 8.0 & $1: 25$ & 83.2 \\
\hline 17 & & & 9.0 & $1: 25$ & 85.0 \\
\hline 18 & & \multirow{5}{*}{3.0} & 7.0 & $1: 25$ & 85.2 \\
\hline 19 & & & 8.0 & $1: 25$ & 94.1 \\
\hline 20 & & & 9.0 & $1: 10$ & 95.5 \\
\hline 21 & & & 9.0 & $1: 25$ & 92.1 \\
\hline 22 & & & 9.0 & $1: 50$ & 90.2 \\
\hline 23 & \multirow{11}{*}{95} & \multirow{6}{*}{1.0} & 7.0 & $1: 25$ & 82.7 \\
\hline 24 & & & 8.0 & $1: 25$ & 83.1 \\
\hline 25 & & & 9.0 & $1: 10$ & 83.3 \\
\hline 26 & & & 9.0 & $1: 25$ & 86.2 \\
\hline 27 & & & 9.0 & $1: 50$ & 88.8 \\
\hline 28 & & & 7.0 & $1: 25$ & 83.4 \\
\hline 29 & & \multirow{3}{*}{2.0} & 8.0 & $1: 25$ & 84.9 \\
\hline 30 & & & 9.0 & $1: 25$ & 85.7 \\
\hline 31 & & & 7.0 & $1: 25$ & 85.0 \\
\hline 32 & & \multirow[t]{2}{*}{3.0} & 8.0 & 1:25 & 90.1 \\
\hline 33 & & & 9.0 & $1: 25$ & 94.9 \\
\hline
\end{tabular}

The first approach included the extraction of uranium into a separate product, followed by purification from thorium-containing impurities by re-extraction with a complexing reagent. In the stage of uranium separation, $5 \%$ tributyl phosphate solutions were used as the extraction mixture, and 50\% tributyl phosphate in S-13 at the stage of REE and thorium extraction. Data on the distribution of the components of the model solution are given in Table 5.

Table 5. The content of REEs, uranium and thorium at various stages of the technological scheme (in $\mathrm{mg} / \mathrm{L}$ ) in the first approach.

\begin{tabular}{cccccc}
\hline & Initial Solution & Raffinate $\mathbf{1}$ & Reextrac U & Raffinate 2 & Reextrac Th \\
\hline $\mathrm{La}$ & 5400 & 5400 & 2 & 5390 & 157 \\
$\mathrm{Ce}$ & 10,000 & 10,000 & 4 & 10,000 & 450 \\
$\mathrm{Nd}$ & 4500 & 4500 & 1 & 4490 & 360 \\
$\mathrm{Th}$ & 2500 & 2120 & 214 & $<0.1$ & 2100 \\
$\mathrm{U}$ & 30 & 1.31 & 29 & $<0.1$ & $<0.1$ \\
\hline
\end{tabular}

It appears that when the proposed extraction scheme for separation and purification of REEs, uranium, and thorium is applied, and when the " $5 \%$ tributyl phosphate-S- 13 " system is used, up to 
90\% U and up to $9.0 \%$ Th are extracted into the uranium branch. At the second stage of the process, the joint extraction of thorium and REEs into 50\% tributyl phosphate in S-13, up to $80 \%$ with REE impurities in the organic phase was extracted into the selective thorium stream. In the aqueous phase, after the extraction of thorium, up to $100 \%$ of REEs remain in the raffinate. Thus, using the proposed scheme, it is possible to extract up to $90 \%$ of thorium from both streams.

The second approach is based on the joint quantitative separation of the sum of uranium and thorium into a separate branch, followed by a separation of the elements by re-extraction with diluted nitric acid under an elevated temperature $\left(30-40{ }^{\circ} \mathrm{C}\right)$, which is traditionally used for the re-extraction of uranium in the Purex process [31]. It was shown that the joint extraction of uranium and thorium into 30\% tributyl phosphate in S-13 with their subsequent joint isolation for re-extraction operations allowed the extraction of $90.74 \%$ of thorium and $78.49 \%$ of uranium (Table 6 ). The REE losses are not more than $4 \%$.

Table 6. The content of REEs, uranium and thorium at various stages of the technological scheme (in $\mathrm{mg} / \mathrm{L}$ ) in the second approach.

\begin{tabular}{cccc}
\hline & Initial Solution & Raffinate & Reextract U + Th \\
\hline $\mathrm{La}$ & 5400 & 5400 & 199 \\
$\mathrm{Ce}$ & 10,000 & 10,000 & 390 \\
$\mathrm{Nd}$ & 4500 & 4500 & 369 \\
$\mathrm{Th}$ & 2500 & 390 & 2270 \\
$\mathrm{U}$ & 30 & $<0.1$ & 23 \\
\hline
\end{tabular}

\section{Conclusions}

In the development of the thorium-uranium fuel cycle, the optimal conditions of the technology for the extraction of thorium from monazite concentrate were identified, including the processes of grinding, opening of mineral raw materials, transfer of target components into a solution, followed by extraction, separation, and purification of uranium, thorium, and REEs.

In particular, the following optimal conditions for opening the monazite concentrate were determined: the action of $19 \mathrm{~mol} / \mathrm{L} \mathrm{NaOH}$ on mineral raw materials ground to particles ranging in size from 0.05 to $0.125 \mathrm{~mm}$ at $\mathrm{S} / \mathrm{L}=1: 4$ and the contact time of $3 \mathrm{~h}$ at $160{ }^{\circ} \mathrm{C}$. The maximum process yield reaches $96 \pm 2 \%$. The resulting phosphate-alkaline solution is free of radionuclides and can be used to produce $\mathrm{Na}_{3} \mathrm{PO}_{4}$ as a mineral fertilizer.

It was shown that the quantitative washing of the products of the alkaline opening of monazite concentrate from the residues of $\mathrm{NaOH}$ and $\mathrm{Na}_{3} \mathrm{PO}_{4}$ to the content of phosphate ions in wash water $<10^{-3} \mathrm{~g} / \mathrm{L}$ is achieved with a single $10 \mathrm{~min}$ contact with distilled water at a temperature of $80{ }^{\circ} \mathrm{C}$ and $\mathrm{S} / \mathrm{L}=1: 10$.

Two versions of the extraction of thorium from its nitric acid solutions containing REEs and uranium were developed. The first variant starts with the separation of thorium together with REEs from uranium impurities due to its transfer to a 5\% solution of tributyl phosphate in S-13. Further extraction of thorium from REEs is carried out by the extraction method using a $50 \%$ solution of tributyl phosphate in S-13. In the first variant, it becomes possible to extract up to $90 \%$ of thorium, up to $90 \%$ of uranium and up to $100 \%$ of REEs. The second option proposes the joint extraction of uranium and thorium into a 30\% tributyl phosphate solution in S-13, followed by elemental separation during the re-extraction operations with the extraction of up to $90 \%$ of thorium and up to $78 \%$ of uranium. Up to $96 \%$ of REEs remain in the aqueous phase during extraction.

Author Contributions: Formal analysis, O.F.; Investigation, E.V. and S.K.; Methodology, O.F.; Project administration, B.M. and M.V.; Resources, O.F.; Writing—original draft, I.T.; Writing-review \& editing, B.M. and M.V. All authors have read and agreed to the published version of the manuscript.

Funding: This study was financially supported by the RFBR grant No. 18-29-24138.

Conflicts of Interest: The authors declare no conflict of interest. 


\section{References}

1. Ulyanin, Y.A.; Kharitonov, V.V.; Yurshina, D.Y. World nuclear energy development scenarios. Proc. Univ. Nucl. Energy 2017, 4, 5-16. Available online: http://atomicexpert.com/page5816224.html (accessed on 21 August 2020).

2. Jordan, B.W.; Eggert, R.G.; Dixon, B.W.; Carlsen, B.W. Thorium: Crustal abundance, joint production, and economic availability. Resour. Policy 2015, 44, 81-93. [CrossRef]

3. Meerson, G.A. (Ed.) Thorium; State Publishing House of Literature in the Field of Atomic Science and Technology; Nauka: Moscow, Russia, 1962; p. 304.

4. Suglobov, D.N.; Yakovlev, R.M.; Myasoedov, B.F. Thorium-Uranium Fuel Cycle for the Heat and Power Industry. Radiochemistry 2007, 49, 385-392. [CrossRef]

5. Boyko, V.I.; Vlasov, V.A.; Zherin, I.I.; Maslov, A.A.; Shamanin, I.V. Thorium in the Nuclear Fuel Cycle; TPU: Tomsk, Russia, 2006; p. 360.

6. Herring, J.S. Uranium and thorium resources. In Nuclear Energy; Springer: New York, NY, USA, 2013; pp. 463-490.

7. Cuney, M. Uranium and thorium: The extreme diversity of the resources of the world's energy minerals. In Non-Renewable Resource Issues; Springer: Dordrecht, The Netherlands, 2012; pp. 91-129.

8. The Global Market for Rare-Earth Metals: Application and Consumption, Part 2. Metall. Bull. 2012. Available online: http://www.metalbulletin.ru (accessed on 5 July 2020).

9. Tikhonov, M.N.; Muratov, O.E.; Petrov, E.L. Solving Radiation Problems of Nuclear Energy in the Strategy of the Uranium-Thorium Cycle. Ecol. Ind. Prod. 2006, 3, 51-53.

10. Smirnov, Y.V.; Efimova, Z.I. Nuclear energy fuel cycle abroad (status, problems, forecasts). Nucl. Technol. Abroad 1961, 2, 20-29.

11. Gavrilin, V.I.; Zubkov, L.B.; Petrova, N.V. Mineral Raw Materials. Thorium. Directory; Geoinformmark CJSC: Moscow, Russia, 1998; p. 27.

12. Kosynkin, V.D.; Kotova, V.M.; Shatalov, V.V. Status of the Problem of Thorium in Russia. Chem. Technol. 2004, 3, 30-34.

13. Dekusar, V.M.; Nikolaev, A.I.; Mayorov, V.G.; Zilberman, B.Y.; Kolesnikova, M.S. Mineral-raw materials base of naturally radioactive raw materials containing Thorium. Atomic Energy 2011, 111, 140-147.

14. Kalinnikov, V.T.; Nikolaev, A.I.; Zakharov, V.I. Hydrometallurgical Complex Processing of Unconventional Titanium-Rare-Metal and Aluminosilicate Raw Materials; Kola Science Center, Russian Academy of Sciences: Apatity, Russia, 1999; p. 225.

15. Arkhangelskaya, V.V.; Kalish, E.A.; Sokolov, Y.F. Unique Complex (Ta-Nb-Zr-Y-REE) Rare Metal Katuginsky Deposit with Cryolite (Eastern Siberia). In Strategy for the Use and Development of the Mineral Resource Base of Rare Metals of Russia in the 21st Century. Reports of the International Symposium, Moscow, October 5-9, 1998; All-Russian Scientific-Research Institute of Mineral Resources: Moscow, Russia, 2000; Volume 1, pp. 41-66.

16. Kosynkin, V.D.; Makarov, V.I.; Gavrilin, V.M. Technology for Processing Monazite Concentrates. In Strategy for the Use and Development of the Mineral Resource Base of Rare Metals of Russia in the 21st Century. Reports of the International Symposium, Moscow, October 5-9, 1998; All-Russian Scientific-Research Institute of Mineral Resources: Moscow, Russia, 2000; Volume 2, pp. 107-111.

17. Petrova, N.V.; Ostroumov, G.V.; Epshtein, E.M. Complex Processing of Niobium-Rare-Earth-Phosphate Ores by the Hydrometallurgical Method. In Strategy for the Use and Development of the Mineral Resource Base of Rare Metals of Russia in the 21st Century. Reports of the International Symposium, Moscow, October 5-9, 1998; All-Russian Scientific-Research Institute of Mineral Resources: Moscow, Russia, 2000; Volume 2, pp. 145-149.

18. Bykhovsky, L.Z.; Kudrin, V.S.; Usova, T.Y. The Value of Loparite Ores in the Mineral Resource Base and the Production of Rare Metals. The Development of the Rare Metal Industry in Russia Based on Loparite. In Proceedings of the Collection of Papers of IV Scientific Conference, St. Petersburg, Russia, 22-24 May 2001; pp. 69-75.

19. Gabaraev, B.A.; Shatalov, V.V.; Rozhkov, V.L.; Smetannikov, V.P. Justification of the Investment Objectives of the Processing Complex of Monazite Concentrate, "Uralmonazit" State Institution 418.6-002-1-1; General Explanatory Note (Volume 1, Album 1); Ministry of the Russian Federation for Atomic Energy and Government of the Sverdlovsk Region: Moscow, Russia, 2001; pp. 1-60. 
20. Zelikman, A.N.; Korshunov, B.G. Metallurgy of Rare Metals. Textbook for Universities, 2nd ed.; Metallurgy: Moscow, Russia, 1991; p. 432.

21. Shaeri, M.; Torab-Mostaedi, M.; Kelishami, A.R. Solvent extraction of thorium from nitrate medium by TBP, Cyanex272 and their mixture. J. Radioanal. Nucl. Chem. 2015, 303, 2093-2099. [CrossRef]

22. Samsonov, M.D.; Trofimov, T.I.; Kulyako, Y.M.; Vinokurov, S.E.; Malikov, D.A.; Batorshin, G.S.; Myasoedov, B.F. Supercritical Fluid Extraction of Rare-Earth Elements, Thorium from Monazite Concentrate and Phosphogypsum Using Carbon Dioxide Containing Tributyl Phosphate and di-(2-ethylhexyl) Phosphoric Acid. Radiochemistry 2015, 57, 291-294. [CrossRef]

23. Xiong, X.H.; Tao, Y.; Yu, Z.W.; Yang, L.X.; Sun, L.J.; Fan, Y.L.; Luo, F. Selective extraction of thorium from uranium and rare earth elements using sulfonated covalent organic framework and its membrane derivate. Chem. Eng. J. 2020, 384, 123240. [CrossRef]

24. Borai, E.H.; Abd El-Ghany, M.S.; Ahmed, I.M.; Hamed, M.M.; El-Din, A.S.; Aly, H.F. Modified acidic leaching for selective separation of thorium, phosphate and rare earth concentrates from Egyptian crude monazite. Int. J. Miner. Process. 2016, 149, 34-41. [CrossRef]

25. Amer, T.E.; Abdella, W.M.; Wahab, G.A.; El-Sheikh, E.M. A suggested alternative procedure for processing of monazite mineral concentrate. Int. J. Miner. Process. 2013, 125, 106-111. [CrossRef]

26. Kumari, A.; Panda, R.; Jha, M.K.; Kumar, J.R.; Lee, J.Y. Process development to recover rare earth metals from monazite mineral: A review. Miner. Eng. 2015, 79, 102-115. [CrossRef]

27. He, L.; Jiang, Q.; Jia, Y.; Fang, Y.; Zou, S.; Yang, Y.; Yang, Y. Solvent extraction of thorium (IV) and rare earth elements with novel polyaramide extractant containing preorganized chelating groups. J. Chem. Technol. Biotechnol. 2013, 88, 1930-1936. [CrossRef]

28. Meerson, G.A.; Uspenskaya, T.A. Improvement of the Alkaline Decomposition of Monazite. At. Energy 1957, $3,259$.

29. Medvedev, V.P.; Semenov, M.A.; Fedorova, O.V.; Tananaev, I.G. Behavior of Natural Radionuclides in the Process of Alkaline Processing of Monazite Concentrate. Bull. Far East. Branch Russ. Acad. Sci. 2016, 1, $53-58$.

30. Sarychev, G.A.; Strikhanov, M.N. Rare earth metals raw materials sources development, program method and comprehensive approach to REM production facilities creation. Tsvetnye Met. 2012, 3, 5-12.

31. ENS (European Nuclear Society). PUREX Process. 2020. Available online: https://www.euronuclear.org/ glossary/purex-process/ (accessed on 21 August 2020).

(C) 2020 by the authors. Licensee MDPI, Basel, Switzerland. This article is an open access article distributed under the terms and conditions of the Creative Commons Attribution (CC BY) license (http://creativecommons.org/licenses/by/4.0/). 